\title{
O PESO DO MARTELO. A PENA CAPITAL NO AFEGANISTÃo, IRÃ E NIGÉRIA
}

\author{
THE HAMMER WEIGHT. \\ CAPITAL PUNISHMENT IN AFGHANISTAN, IRAN AND NIGERIA
}

\author{
Thiago Perez Bernardes de Moraes \\ Pós-doutorado em direito (UNIME) \\ Centro Universitário Campos de Andrade \\ Curitiba / PR / Brasil \\ thiago.moraes@uniandrade.edu.br
}

\begin{abstract}
Resumo: Desde os primórdios da história humana a pena de morte esteve presente como uma forma de se punir transgressões, das mais diversas. Na segunda metade do século XX viu-se surgir uma tendência abolicionista em relação à pena capital, com muitos países ratificando tratados internacionais e também abolindo a pena de morte de suas legislações. Neste breve ensaio é discutido o uso da pena de morte no Afeganistão, Irã e Nigéria. Em comum estes são países são retencionistas em relação à pena capital e que são reiteradamente acusados de não fornecerem as salvaguardas promulgadas pelo direito internacional. Estes são países influenciados significativamente pela Sharia, o que se reflete diretamente no padrão de punição criminal que prevê o uso da pena de morte como mandatória para uma série de situações, inclusive para crimes não hediondos.
\end{abstract}

Palavras-chave: Afeganistão; Irã; Nigéria.

Abstract: Since the beginning of human history, the death penalty has presented itself as a means to punish the most diverse transgressions. In the second half of the twentieth century, an abolitionist tendency in relation to capital punishment emerged, which led many countries to ratify international treaties and also to abolish the death penalty in their legislation. This brief essay discusses the use of the death penalty in Afghanistan, Iran and Nigeria. In common, these are countries that are retained in relation to capital punishment and that are repeatedly accused of not providing the safeguards imposed by international law. These three countries are significantly influenced by Sharia law, which is directly reflected in the pattern of criminal punishment, where the death penalty is mandatory for a number of situations (including nonheinous crimes).

Keywords: Afghanistan; Iran; Nigeria.

MORAES, Thiago Perez Bernardes de. O peso do martelo. A pena capital no Afeganistão, Irã e Nigéria. Revista Thesis Juris - RTJ, São Paulo, v. 10, n. 1, p. 1-15, jan./jun. 2021.

http://doi.org/10.5585/rtj.v10i1.10841. 


\section{Introdução}

Toda punição, incluindo a pena de morte, traz imposição de "sofrimento" ao ofensor com base no crime cometido. Ao longo da história a sociedade sempre usou a punição para desencorajar potenciais infratores de realizar atividades criminosas. Nesta conjuntura, a pena de morte é tão antiga quanto à própria sociedade humana, tendo sido aplicada em quase todos os agrupamentos humanos já conhecidos como forma de punição por delitos claramente definidos (MORAES, 2016 p.224-230; OBARISIAGBON, 2017, p.95-96).

O pesquisador Dave McRae (2017, p.2-9) esquadrinha alguns fatores importantes sobre a tendência de abolição da pena de morte nas mais diversas constituições contemporâneas. Nessa linha, o primeiro destaque é a democratização, sobretudo, nos estágios iniciais, onde a abolição serve como uma mensagem de que o país está disposto a espantar os resquícios autoritários do passado. O tipo da liderança política também é importante, vide que políticos de esquerda são os mais propensos a se colocarem como favoráveis à abolição da pena de morte. Não obstante, a pena de morte vem deixando de ser discutida como uma questão de justiça criminal, para ser tratada como um tema de direitos humanos, em um movimento que se deu concomitante a formulação e implantação de mecanismos internacionais de direitos humanos. Tomados em conjunto, tais instrumentos, facilitaram a criação de um nicho permeável à pressão externa pela abolição da pena de morte. No que diz respeito à dinâmica regional, quanto maior for à quantidade de vizinhos que determinado país tem que aboliram a pena de morte, maior a probabilidade de este também aderir à abolição. Denota-se também que o Islã pode ter um papel impeditivo quanto à abolição da pena de morte, visto que a maioria dos países com populações majoritariamente muçulmanas mantém a pena de morte.

Nessa mesma lógica, vale ressaltar que um drama poderoso e um intenso simbolismo envolvem a pena de morte, e isso por sua vez tem assegurado a essa um papel desproporcional no discurso público sobre criminalidade e justiça. Considerando que "drama" aqui pode ser definido segundo o que alvitra Susan A. Bandes (2018, p.920-922) como uma "taquigrafia política" ou como a capacidade de apelar ao emocional de uma audiência de forma visceral, pode-se dizer que a pena capital é mister neste diapasão.

Este trabalho se debruça em três países que vivem o "drama" da pena de morte e a hipótese aqui é que, nem o direito internacional e nem as forças internas criaram um cenário propício para o estabelecimento da abolição ou para a garantia de que esta fosse reservada apenas aos crimes mais graves em um cenário onde as mais rigorosas garantias processuais são observadas. 
Essa hipótese se baseia no fato de que tanto no Afeganistão, quanto no Irã e na Nigéria, existe o uso da pena de morte mandatória para uma série de crimes não hediondos, além disso, os três países são fortemente influenciados pelo Islã e o uso da pena de morte aqui é balizado pela Sharial. Nos três casos, ao que parece, o uso da pena de morte extrapola a busca do controle social e da redução da criminalidade, atacando as liberdades individuais e sendo um poderoso instrumento de dissuasão de oposições políticas. Este trabalho tem cunho exploratório e tem como objetivo trazer um quadro sobre o uso da pena de forma tanto em forma quanto em natureza, no Afeganistão, Irã e Nigéria por meio de revisão de literatura.

\section{Desenvolvimento}

\section{Afeganistão}

O Afeganistão apresenta um quadro único do ponto de vista dos estudos jurídicos e sociais. $\mathrm{O}$ atual estado da arte jurídico, fragmentado e desatualizado traz desafios significativos ao pensamento e à análise acadêmica. Ahmed Hamdy Tawfik (2009, p. 667) sugere que no Afeganistão moderno, um dos principais problemas para o universo das lutas jurídicas é a identificação do conceito de crime. Mesmo o Afeganistão tendo definido como paradigma o Código Penal Secular Afegão de 1976, destaca-se que as leis islâmicas, a jurisprudência dos tribunais e as tradições têm precedência na vida cotidiana dos afegãos. A jurisprudência do tribunal e o sistema tradicional de resolução de disputas são considerados como um fruto da jurisprudência islâmica, além disso, em alguns casos eles representam interpretações e aplicações visivelmente errôneas (distorcidas) da Sharia. Nesse cabimento evidencia-se que o conceito de crime sob as premissas do sistema de justiça criminal afegão são baseadas principalmente em tradições e costumes ao invés da lei islâmica em sentido stricto. Existe aí um triângulo onde em uma ponta tem-se o judiciário, em outra, o entendimento da sociedade e no terceiro polo, estende-se o que é estipulado pela Sharia. O código penal aqui é extremamente fragmentado e precisa ser atualizado de maneira a fornecer descrições precisas sobre os crimes, além disso, a política criminal afegã demanda mais clareza (TAWFIK, 2009, p.670-676).

No Afeganistão existe o regime da pena de morte mandatória para alguns crimes, conforme os termos do Artigo $1^{\text {o }}$ do Código Penal de 1976, com sanções que se baseiam na

\footnotetext{
${ }^{1}$ De maneira simplificada a Sharia pode ser compreendida como a base do sistema legal dentro do Islã. A Sharia deriva diretamente das páginas do Alcorão, assim como, das interpretações realizadas por estudiosos do islã. A lei Sharia é empregada como um "código de vida" onde todos os muçulmanos devem seguir seus preceitos, não obstantes, alguns países adotam esse sistema como a base geral de todo arcabouço legal. Traduzindo, o termo Sharia significa "trilha clara bem delineada para a água" (BAKHT, 2004, p.5-12).
} 
escola Hanafi do islamismo sunita. Dentro deste princípio, entretanto, existe a possibilidade de que o parente da vítima possa escolher perdoar o infrator ou ainda aceitar o pagamento de Diyah (uma compensação em dinheiro pelo "sangue derramado"), mas ainda assim, tem-se uma pena de morte mandatória, pois, não cabe ao judiciário escolher se a pena de morte será ou não aplicada e sim a família da vítima. Ainda no Artigo $1^{\circ}$ do Código Penal, existe a previsão de penas de Hudud por algumas infrações como a Hirabah (pirataria ou guerra ilegal), Zina (ofensa sexual) e furto. É difícil saber se no Afeganistão, em prática, todas estas regras são assistidas, independentemente de o país ser signatário ou não das normas do direito internacional. $\mathrm{O}$ paradoxo aqui reside no fato de que a Constituição do Afeganistão prever que a lei deve ser aplicada de forma consistente a obrigações e padrões internacionais e também aos princípios da Sharia. Nesse ponto a posição internacional é clara ao afirmar que a pena de morte obrigatória viola o direito a não arbitrariedade e a proteção do direito à vida (CORNELL CENTER ON THE DEATH PENALTY WORLDWIDE, 2017, p.1-2).

Não é possível falar sobre pena de morte no Afeganistão sem levar em conta a construção histórica e social do país. Grant Farr (2017, p.156-161) nesse ponto alvitra que nas últimas três décadas o país passou por uma turbulenta sequência de guerras e conflitos, o que o deixou completamente devastado. Nesse eixo, apesar da relativa estabilidade política do governo Karzai, muitas tensões e conflitos se permearam logo abaixo da superfície visível da sociedade. Entre tais tensões estão os conflitos étnicos, linguísticos, religiosos e sectários. Tais conflitos, sempre estiveram presentes no país, mas, foram fundamentalmente alterados ao longo de décadas por guerras, revoluções e insurgências. Muitos grupos existentes até hoje estiveram presentes nos esforços para expulsar a União Soviética na década de 1980 do país e também mais tarde lutaram pela independência do Afeganistão.

É difícil obter dados precisos sobre as execuções (um segredo de estado), mas, estimase que ocorreram pelo menos 65 entre 2007-2017. Quanto aos métodos de execução, existe a prescrição do enforcamento e do pelotão de fuzilamento. Além disso, existem outras práticas menos comuns como o apedrejamento. Quanto à pena de morte mandatória, ela é prevista para o crime de assassinato e também para os crimes de Zina, como adultério e estupro. No entanto existem algumas exceções, dentre estas, destaca-se que menores de 18 anos e gestantes não podem ser executados. Além disso, todos os afegãos têm direito a representação legal, contudo, existe uma grave escassez de advogados em todo país e por conta disso os julgamentos sem representação legal são bastante comuns. Se não bastasse, o sistema de justiça é muito fragilizado, em um cenário marcado por problemas de corrupção, falta de funcionários treinados 
e ausência de técnicas de investigação adequadas (CORNELL CENTER ON THE DEATH PENALTY WORLDWIDE, 2017, p.3).

\section{Irã}

O Irã não é apenas mais um país islâmico, antes disso, trata-se da única teocracia ${ }^{2}$ do mundo moderno que tem seu nascimento marcado por uma revolução que envolveu extrema violência (irrompida por todo país). Nesse entendimento é válido destacar que estados autoritários repousam em um arcabouço de leis e códigos jurídicos vagos que dão às elites dominantes amplos poderes para exercerem uma justiça seletiva contra aqueles que desafiam seu poder absoluto. Como consequência, em três décadas, o Irã passou a ser classificado como uma das nações que mais realiza execuções em todo o mundo. Não obstante, tais leis extremamente vagas acomodam a facção conservadora e os clérigos associados ao Estado para empregar "critérios islâmicos" de justiça, bloqueando, por assim dizer, o acesso aos direitos civis. É possível dizer que por meio da legislação e da propaganda de Estado o governo do Irã, hoje, controla as formas institucionais e simbólicas de violência que balizam a relação entre Estado e indivíduos (DANESH; SADR, 2014, p.1-3; SHARIFIAN; FEKRIPOUR; HEIDARPOUR, 2020, p.68-76).

É preciso levar em conta os aspectos históricos, isso considerando que o Irã é um país muçulmano desde meados do século VII e que, além disso, o islamismo Xiita tornou-se ramo predominante, com Sunitas e outras minorias existindo ainda apenas em pequenos enclaves. Em 1925 o Irã moderno começa a de fato se erguer com a derrubada da dinastia Qajar e a substituição desta pelo rei Reza Shah Pahlavi. Mais adiante, em 1978, em uma revolução patrocinada por tradicionalistas islâmicos, o rei foi derrubado e no lugar ascendeu o aiatolá Khomeini que a partir de então passou a ocupar a figura de líder da República Islâmica do Irã (FAUTRÉ; IMAN; TIMMINS, 2012, p.3-6). De acordo com o Artigo 4º da Constituição do Irã, todos os tipos de legislações vigentes no país, sejam estas leis, regulamentos civis, penais, financeiros, econômicos, administrativos, culturais, militares, políticos e outros, devem ser baseados nos critérios islâmicos (GHASSEMI, 2009, p.162-168).

De forma bastante semelhante ao Afeganistão, no Irã, existe pena de morte obrigatória para algumas infrações, como assassinato, sendo que apenas reivindicações advindas de parentes das vítimas podem libertar o agressor (ou o inocente que não conseguiu corroborar sua

\footnotetext{
2 Após o ano de 1979, quando ocorre a revolução islâmica, o relativamente moderno sistema de justiça criminal do Irã é imediata mente substituído por um sistema de justiça criminal islâmico baseado na versão xiita da lei da Sharia. Este sistema se consolidou durante o mandato do aiatolá Ruhollah Musavi Khomeini (ALASTI, 2009, p.12-23).
} 
ausência de culpa). O Irã declara-se uma República Islâmica, como bem indaga Silvia Tellenbach (2009, p.690-698), por conta disso, todas as leis e regulamentos devem se lastrear em premissas islâmicas, seguindo a interpretação da escola Shi'ite dja-farī. Em razão disso, a lei islâmica é aplicada de forma ampla, ou seja, compreendendo todos os problemas legais cotidianos de um Estado moderno, que conta com mais de 74 milhões de habitantes. Há de se considerar também que a posição do Irã na comunidade internacional deve estar de acordo com os princípios da lei islâmica, e o que se evidencia nesse sentido, não é exatamente um total antagonismo de princípios, mas, uma falta de entendimentos entre os pontos de convergência e divergência entre a lei islâmica e a lei ocidental. Tahirih Danesh e Shadi Dadr (2014, p.1-2) pontuam que o sistema de justiça criminal da República Islâmica do Irã pode ser descrito, sumariamente, como um estado de vigilância que não demonstra nenhuma inclinação e ou respeito pela vida civil.

Com efeito, no ano de 2017 aproximadamente 4.500 pessoas, incluindo mais de 150 jovens, foram condenados à pena de morte no Irã. Apesar do sigilo, é possível estimar que pelo menos 506 execuções foram realizadas no ano de 2017. Estima-se que entre 2007 e 2016 houveram por volta de 5.314 execuções. A lista de crimes puníveis com a pena de morte é ampla e inclui aqui os que resultam ou não em morte. Podemos destacar, por exemplo, assassinato, infrações relacionadas à morte por conta de terrorismo, e também infrações que não resultam em morte como: violação, roubo, sequestro, tráfico e posse de drogas, crimes econômicos, adultério, apostasia, traição, espionagem, infrações militares, relações homossexuais, pornografia, crimes políticos, consumo de bebidas e blasfêmia. Destaca-se como agravante que a pena de morte é mandatória para a maior parte destes crimes supramencionados.

Os professores Mahmood Amiry-Moghaddam e Tabassom Fanaian (2014, p.43-51) ensinam que o Irã (depois da China) é o país com o maior número de execuções, todavia, segundo observações de organizações de direitos humanos acredita-se que o número real de execuções é muito maior do que o relatado ${ }^{3}$. Além disso, vale lembrar que a maior parte dos executados é em virtude de crimes comuns, como posse e tráfico de drogas. Ademais, é importante ressaltar que existe uma correlação positiva entre eventos políticos e o número de execuções, nesse caso, a pena de morte estaria sendo usada (segundo críticos) como instrumento repressivo para espalhar medo na sociedade iraniana. Destaca-se também que, em comparação com os demais países desta lista, o Irã é o país com maior volume de execuções públicas, sendo

\footnotetext{
${ }^{3}$ Este número pode ser ainda mais elevado, principalmente se levarmos em conta as "execuções secretas" ou não anunciadas (AMIRY-MOGHADDAM; FANAIAN, 2014, p.19-21).
} 
que estas são geralmente realizadas durante as manhãs em partes centrais das cidades usando guindastes que provocam a morte por asfixia em um processo que pode levar até 15 minutos, o que leva esta execução a ser conhecida como sufocamento prolongado, caracterizando-se como tortura. A maior parte destas execuções ocorre nas cidades de Shiraz, Teerã, Karaj e Isfahan.

Willy Fautré, Amal Iman e Flint Timmins (2012, p.11-12) sublinham também que no Irã, assim como no Afeganistão e na Nigéria, outras execuções públicas violentas são comuns, como o apedrejamento. Aliás, é interessante destacar que o apedrejamento foi incorporado ao Código Penal Iraniano como punição para adultério em 1983, e apesar de em 2002 uma moratória ter sido perpetrada sobre o uso de apedrejamento, este ato foi apenas simbólico, vide que não teve peso legal, e a prática em questão continua recorrente. É interessante que as autoridades iranianas consideram o apedrejamento não como uma forma de execução, mas sim como uma punição, uma vez que o Código Penal garante clemência aos que conseguem escapar e ou sobreviver ao apedrejamento (estima-se que menos de $50 \%$ das vítimas sobrevivem, com graves sequelas).

Quanto às garantias mínimas destacam-se três pontos: a proibição da aplicação da pena para menores de 18 anos, mulheres grávidas ou indivíduos mentalmente doentes. Quanto ao primeiro ponto, a execução de menores de idade no Irã é legítima e de acordo com o Artigo $91^{\circ}$ do Código Islâmico é permitida a execução se os juízes considerarem o menor maduro o bastante para entender a natureza da infração. Quanto ao segundo ponto, existe uma salvaguarda, vide que o artigo $6^{\circ}$ do Código Penal Iraniano prevê que uma mulher não pode ser executada enquanto grávida. Quanto ao último ponto, existe uma salvaguarda prevista no artigo $51^{\circ}$ do Código Penal Iraniano de 1991, porém, na prática, se ficar corroborado que o indivíduo foi acometido por uma doença mental após a prisão é permitida a execução. Da mesma forma, outro fato que salta aos olhos é que o Irã é o maior executor de indivíduos com menos de 18 anos. Relatórios de organizações de direitos humanos indicam que dezenas de adolescentes anualmente são condenados. Existem evidências também de que a pena de morte é usada para sufocar dissidências políticas, em especial, as advindas das minorias étnicas. De um lado, a lei iraniana prevê que todo arguido que enfrenta a pena de morte tem direito a representação de um advogado e para isso o governo oferece assistência gratuita aos que não podem pagar. Todavia, os advogados só são disponíveis no estágio do julgamento e os réus não têm acesso à representação durante a prisão, ou durante investigações e interrogatórios. Na realidade, muitos condenados nunca receberam qualquer representação legal. Além disso, na prática não há aqui a presunção de inocência (CORNELL CENTER ON THE DEATH PENALTY WORLDWIDE, 2017, p.4-5). 
Com base em evidências empíricas, Tahiri Danesh e Shadi Sadr (2014, p.1-4) desenvolvem algumas recomendações a serem assistidas pelas autoridades políticas e governamentais do Irã para que se aperfeiçoem as práticas dos direitos humanos na região:

1. Fornecer encorajamento para que autoridades do Irã assinem instrumentos internacionais, incluindo a Convenção das Nações Unidas sobre a eliminação de todas as formas de discriminação contra as mulheres e a Convenção das Nações Unidas contra a tortura;

2. Criar formas de responsabilizar as autoridades e órgãos do Irã que promovam a cultura da violência, dentro e fora das fronteiras iranianas;

3. Incentivar o estado de direito e os processos que envolvem comissões da verdade e tribunais que se concentram em defender as vítimas de violações dos direitos humanos, principalmente mulheres e minorias religiosas e étnicas;

4. Facilitar o amadurecimento das relações internacionais entre os líderes comprometidos com os direitos humanos e as autoridades iranianas.

\section{Nigéria}

A Nigéria é um país que de longa data é influenciado pelo Islã, entendendo que a religião dominante de hoje chegou ao país a mais de 500 anos, em 1493, quando a região foi conquistada por invasores muçulmanos liderados por Askia Muhammad Touré. Durante os séculos posteriores houve a ascensão e a queda de muitos estados muçulmanos na região. Em 1905 a maior parte do país estava sobe controle dos britânicos, enquanto a região norte foi governada indiretamente o que permitiu que a prática do islã e a Sharia se mantivessem presentes. Nas décadas seguintes, um clima de tensão religiosa varreu o país desencadeando um intenso conflito. Desde 2000, 12 dos 37 Estados da Nigéria têm sido governados com base na Sharia (FAUTRÉ; IMAN; TIMMINS, 2012, p.3-5). A Nigéria, segundo Peiffer (2005, p.507-521) é o país mais populoso da África Ocidental e se destaca como um país dotado de contradições perturbadoras:

1. Apesar de se tratar de um país rico no que tange a disponibilidade de recursos naturais e humanos, a pobreza é amplamente disseminada;

2. Os mais recorrentes problemas nigerianos são comuns a outros países (fraco desempenho e distribuição econômica, instabilidade política, conflitos sociais e corrupção), todavia, o país se destaca entre a maior parte dos demais, pois tanto a 
magnitude, quanto a persistência destes problemas, segue um padrão considerado elevado em perspectiva comparativa;

3. Em larga proporção existe uma notável ausência regulatória, concomitante com uma pobre governança por parte do Estado.

A Nigéria vem estabelecendo em boa parte do território a lei criminal da Sharia e vale sublinhar que em boa parte dos casos parece possível a incorporação das proteções processuais e as salvaguardas que a lei islâmica tradicional geralmente associa à pena de morte (NELSON; PATES, 2017, p.2-4). A legitimidade autocrática estendida a indivíduos e grupos de elite subvertem as leis criminais, levando a punição a ser explorada de maneira perversa, conforme descreve Viviane Saleh-Hanna (2008, p.43-49) no que se refere ao confronto compreendendo o poder socioeconômico e a influência política sobre prisões e confinamentos. Isso faz se estabelecer noções desiguais de crime e punição limitando frontalmente a aplicação correta das sanções penais. A Constituição da Nigéria é pragmática no que diz respeito às leis relativas a crimes e a punições. Os propósitos idealmente igualitários na Nigéria são distorcidos por conta da grande corrupção e apadrinhamento por parte da legislatura. Tanto o sistema penal, quanto o controle social nigeriano estão conectados umbilicalmente à liderança política e orientados para a concessão de governança e garantia do status quo dos poderosos.

Na Nigéria o conceito de pena de morte tem sido encarado como controverso. De um lado a maioria dos nigerianos têm opiniões e argumentos fortes para apoiar um dos lados da divisão (contra e favoráveis), de outro, os argumentos para ambos os lados podem ser extremamente convincentes, alimentando a controvérsia da pena de morte na Nigéria. Isso foi o que o que levou o tema a se tornar mais saliente durante o mandato do ex-presidente Olusegun Obasanjo que de maneira geral, se recusou a aceitar a pena de morte (OBARISIAGBON, 2017, p.96-97).

Voltando ao passado na história do sul da África, é evidente a forma como os políticos manipulam a pena de morte em seu benefício e a utilizaram como uma arma política. A lei de homicídio, por exemplo, que distingue entre assassinato e homicídio culposo também decidiram quem deveria ou não ser executado. Nesse nexo, havia uma tendência nos casos em que a vítima era europeia e o criminoso não europeu de se considerar o crime como doloso. Isso se plasmou consistentemente em um estudo pormenorizado do uso da pena de morte na Nigéria, onde se aferiu que o uso fora marcado, sobretudo, por razões políticas em vez de justiça, perpetradas principalmente para calar dissidentes e adversários políticos, em um cenário marcado por injustiça e arbitrariedade. Não há dúvida de que o estabelecimento de tribunais da Sharia 
cumpriu a demanda dos interesses políticos dos líderes muçulmanos, que dominaram a política nigeriana e o exército desde a independência do país (KARIMUNDA, 2011, p.26-34). Nesse entendimento, a manutenção da pena de morte pode ser entendida como um epifenômeno desta tendência. Por conta desse passado histórico, mesmo que a Nigéria inicie um acordo dentro dos tratados internacionais que preveem a abolição da pena de morte (ou seu uso restrito a crimes graves), este tratado só terá força de lei, de acordo com o Artigo $12^{\circ}$ da Constituição, quando for aprovado internamente como lei (OBARISIAGBON, 2017, p.91-94).

Viviane Saleh-Hanna (2008, p.18-29) assevera ainda nessa lógica que o sistema de justiça criminal nigeriano sofre com atrasos em mais de quatrocentas instituições penais públicas, em cenários caóticos onde reclusos com deficiência mental, crianças e jovens são de forma comum encarcerados junto com a população de presos adultos. A história política da Nigéria influenciou frontalmente o desenvolvimento de leis penais e políticas condenatórias. É neste eixo que os críticos argumentam que na maior parte das vezes as leis estão desatualizadas e que muitas foram arbitrariamente forjadas para atender interesses específicos de elites dominantes. Como prevê a Lei das Forças Armadas de 1993, a Lei do Código Criminal e o Código Penal da Sharia do norte da Nigéria, muitos crimes são passiveis de pena de morte mandatória, dentre estes se destacam os assassinatos, o terrorismo, o roubo e a traição, além disso, nos tribunais da Sharia, o adultério e a apostasia também são punidos com a morte.

Nessa esteira a pena de morte tornou-se um motor de controvérsias na Nigéria, pois existem grupos que clamam pela abolição enquanto outros pedem a manutenção da mesma e o uso dela para crimes não graves, como adultério ou tráfico de drogas. Em verdade, o Artigo $36^{\circ}$ da Constituição da Nigéria ordena que uma pessoa não possa ser condenada à morte a menos que tal crime seja definido e a penalidade prescrita em lei. Porém, no Artigo $33^{\circ}$, entende-se que toda pessoa tem o direito à vida, sendo assim, ninguém pode ser privado intencionalmente desta, exceto na execução da sentença de um tribunal. A implicação desta disposição faz da pena de morte na Nigéria um mecanismo legal, ficando aqui estabelecida apenas a necessidade de que o trâmite seja conduzido por um tribunal competente. Não obstante, na disposição da Constituição a pena de morte é uma forma legal de punição e mandatória para uma ampla gama de delitos. Em primeira instância, a implicação disso reside no fato de que em todo julgamento, sempre que o indivíduo é culpado, o juiz se vê de mãos atadas, tendo como única pena a disposição a pena capital. De toda forma, muitas recomendações devem ser assistidas a fim de que a pena de morte seja mais "justa” em sua aplicação na Nigéria. Talvez, o primeiro ponto a se destacar seja o baixo desempenho socioeconômico do país, nesse caso, a queda da criminalidade pode advir não só da repressão, mas também de políticas públicas que fomentem 
oportunidades de emprego remuneradas aos cidadãos (o que diminuiria tanto a pobreza como a desigualdade). Além disso, em nível mais processual, é preciso que ocorra a introdução do método de teste de DNA como impedimento para a execução de inocentes em casos em que indivíduos são acusados de homicídios e outros crimes. Além disso, esforços precisam ser feitos para que a pena de morte seja de fato limitada aos crimes mais hediondos, o que, para tanto, demanda que ocorra mudança na legislação do país (ADEKUNBI, 2018, p.31-39).

\section{Considerações finais}

A pena de morte tem amplo papel simbólico, se enquadra no discurso público como um ponto focal aglutinador de medos, e também é uma poderosa "abreviação ideológica" para no debate sobre política criminal. No caso dos três países analisados Muitas vezes, a aplicação da pena de morte está sujeita a pressões intensas que contribuem por vezes para que ela seja aplicada em um padrão arbitrário, discriminatório e impreciso. Em um sentido amplo, a pena de morte não escapa da política, isso porque, cobrar, julgar e condenar em casos de pena capital é sempre um ato politicamente carregado (BANDES, 2018, p.907-913; NIVEN; DONNELLY, 2020, p.95-102).

Como uma triste realidade incompatível com o século XXI, a pena de morte pode ser comparada analogamente a um tipo de "relíquia medieval", que por sua vez não tem legítimo lugar em sociedades democráticas. É preciso reforçar o entendimento, em âmbito global que compreende a pena de morte como amplamente perversa e disfuncional e, a partir desse entendimento, é possível tornar melhor e mais aderentes novos diplomas legais internacionais que sirvam como obstáculo ao uso da pena de morte. Não existe respaldo de evidências criminológicas que justifiquem o uso da pena de morte, logo, ela é em primeira instância a materialização da negação da dignidade e do valor da pessoa humana, ou seja, ela é algo que se coloca frontalmente contrária a todo arcabouço fundamentado pelos direitos humanos (MORAES, 2019, p.175-179; HUONG; KHOO, 2019, p.3-7).

Nesse entendimento, é indubitável que hoje se faz necessário questionar se a pena de morte é justificável ou se ela é uma ameaça direta ao direito à vida. A própria resposta parece tautológica, visto que a pena de morte é a prática de matar pessoas por vias judiciais como uma punição a delitos. Nesse ponto, a Declaração Universal dos Direitos Humanos reitera um compromisso entre as nações para promover os direitos ditos fundamentais. Aqui, se considera em nível de importância maior o direito à vida, nesse caso, se prevê que ninguém pode ser submetido à tortura ou crueldade, tratamento desumano ou punição degradante. Mas, apesar 
do texto ser abrangente, ele se silencia no que diz respeito a pena de morte, e mais especificamente sobre o fato dela representar ou não uma ameaça ao direito à vida. Tal questão se dá por solucionada em 1994, quando a Assembleia das Nações Unidas deliberou em favor da restrição da pena capital. Dentro do direito internacional, o Pacto Internacional sobre Direitos Civis e Políticos fez reconhecer os direitos relacionados à vida como inalienáveis e supremos, para o qual nenhuma degradação pode ser permitida, mesmo em qualquer tipo de demanda pública ou de massa, assim sendo, não há outra coerência que não a da abolição da pena de morte (MORAES, 2015, p.170-178).

Tanto no caso da Nigéria, quanto do Afeganistão e principalmente do Irã, verificou-se que o uso da pena de morte ocorre sem que as salvaguardas promulgadas pelo direito internacional sejam assistidas, o que de algum modo corrobora nossa hipótese. Nos três países a Sharia se faz bastante presente, porém, sua aplicação para o caso de pena de morte é feita com base em uma interpretação na maior parte das vezes bastante dissonante da ideia original do texto, ou seja, o texto aqui em vez de baliza torna-se um lastro de um processo injusto.

Além disso, no caso dos três países, fica claro que o objetivo do uso da pena de morte vai muito além do controle da criminalidade ou da redução dos comportamentos hediondos na sociedade. Dito de outra forma, a pena capital nesses países tem funcionado como um imponente instrumento político, um disseminador de medos e também um silenciador das vozes dissonantes. Ou seja, a pena capital nesses países é marcada por razões políticas no lugar de justiça, perpetradas principalmente para calar dissidentes, minorias étnicas e adversários políticos, em arenas onde a injustiça e a arbitrariedade são onipresentes. A pena de morte não serve para qualquer propósito ético e é claramente contrária aos ideais de justiça restaurativa. Nesse diapasão é preciso entender que, nestes três países, de um lado, existe a nítida urgência de que estes governos usem seu enorme poder e seus recursos para corrigir as gritantes das desigualdades e injustiças que caracterizam o flagelo social vivido por estas sociedades. Concluindo, de maneira direta e indireta, a pena de morte (ao menos nestes três países) parece servir como um obstáculo (dentre muitos outros) contra o amadurecimento das condições de justiça e também do enraizamento de uma motriz para o fim das desigualdades.

\section{Referências}

ADEKUNBI, Nzeribe Ejimnkeonye Abangwu. Death penalty in Nigeria: to be or not to be: the controversy continues. Arabian Journal of Business and Management Review (OMAN Chapter), Oman, v. 3, ed. 3, p. 23-53, 1 out. 2013. Disponível em: https://citeseerx.ist.psu.edu/viewdoc/download?doi=10.1.1.1080.2024\&rep=rep1\&type=pdf. Acesso em: 5 jun. 2018. 
ALASTI, Sanaz. Cruel and Unusual Punishment: Comparative Perspective in International Conventions, the United States and Iran. Vandeplas Publishing, 2009.

AMIRY-MOGHADDAM, Mahmood; FANAIAN, Tabassom. The death penalty in Iran: Fighting crime or an instrument to spread fear?. London: The Foreign Policy Centre, 2012. Disponível em: http://www.ihrr.org/ihrr_article/violence-en_the-death-penalty-in-iranfighting-crime-or-an-instrument-to-spread-fear/. Acesso em: 13 abr. 2018.

BANDES, Susan. All Bathwater, No Baby: Expressive Theories of Punishment and the Death Penalty. Michigan Law Review, Michigan, v. 116, ed. 6, p. 905-924, 2018. Disponível em: https://repository.law.umich.edu/cgi/viewcontent.cgi?article $=1698 \&$ context=mlr. Acesso em: 2 out. 2018.

CORNELL CENTER ON DEATH PENALTY WORLDWIDE (Eua). Death Penalty Database. Ithaca: Cornell Law School, 2017. Disponível em: https://www.deathpenaltyworldwide.org/search.cfm. Acesso em: 12 jun. 2017.

DANESH, Tahirih; SADR, Shadi. Violence: Introduction. Iran Human Rights Review, London, p.1-6, jan. 2014. Disponível em: http://www.ihrr.org/wpcontent/uploads/ihrr/articles/2014/1//828_violence-en_introduction1.pdf. Acesso em: 13 abr. 2018.

FARR, Grant. The Hazara of Central Afghanistan. In: BROWER, Barbara; JOHNSTON, Barbara Rose. Disappearing Peoples?: Indigenous Groups and Ethnic Minorities in South and Central Asia. 1. ed. New York: Routledge, 2007. p. 146-178. Disponível em: https://www.taylorfrancis.com/chapters/edit/10.4324/9781315430416-13/hazara-centralafghanistan-grant-farr. Acesso em: 2 out. 2018.

FAUTRÉ, Willy; IMAN, Amal; TIMMINS, Flint. Stoning Stoning in Iran, Somalia, Nigeria, Pakistan, Iran, Somalia, Nigeria, Pakistan,Afghanistan Afghanistan Afghanistan \& Sudan. Brussels: Human Rights Without Frontiers Int'1, 2012. Disponível em: http://www.hrwf.net/images/reports/2012/2012\%20stoning\%20final.pdf. Acesso em: 13 abr. 2018.

GHASSEMI, Ghassem. Criminal punishment in Islamic societies: empirical study of attitudes to criminal sentencing in Iran. European journal on criminal policy and research, New York, v. 15, ed. 1, p. 159-180, 2 mar. 2009. Disponível em:

https://link.springer.com/content/pdf/10.1007/s10610-008-9095-2.pdf. Acesso em: 4 jul. 2018.

HUONG, Yu Sin; KHOO, Ying Hooi. Human Rights, State Sovereignty, and the Death Penalty: Indonesia's Diplomacy Approach on Bali Nine. Journal of International Studies, Kedah, v. 15, ed. 1, p. 1-20, 2020. Disponível em: http://ejournal.uum.edu.my/index.php/jis/article/view/8024. Acesso em: 7 nov. 2019.

BAKHT, Natasha. Family Arbitration Using Sharia Law: Examining Ontario's Arbitration Act and its Impact on Women. Muslim World Journal of Human Rights, Rochester, v. 9, n. 3, p. 1-24, 2 fev. 2004. Disponível em: https://www.researchgate.net/profile/Natasha_Bakht/publication/40824050_Family_Arbitrati 
on_Using_Sharia_Law_Examining_Ontario\%27s_Arbitration_Act_and_its_Impact_on_Wom en/links/00463516e93c0d8718000000.pdf. Acesso em: 7 jan. 2019.

KARIMUNDA, Aimé Muyoboke. The Death Penalty in Africa: The Path Towards Abolition. 1. ed. Oxfordshire: Routledge, 2014. 252 p.

KELLY, Brendan; FOLEY, Sharon. Analysis of last statements prior to execution: methods, themes and future directions. QJM: An International Journal of Medicine, Oxford, v. 111, ed. 1, p. 3-6, 2 jan. 2018. Disponível em:

https://academic.oup.com/qjmed/article/111/1/3/4653776. Acesso em: 8 maio 2018.

MCRAE, Dave. Indonesian Capital Punishment in Comparative Perspective. Journal of the Humanities and Social Sciences of Southeast Asia, Leiden, v. 173, ed. 1, p. 1-22, 2 jan. 2017. Disponível em: https://brill.com/view/journals/bki/173/1/article-p1_1.xml. Acesso em: 10 set. 2018.

MORAES, Thiago Perez Bernardes de. Pena de morte nas páginas do The New York Times: Um estudo sobre a relação entre punição capital, eleições e opinião pública. Revista Internacional de Investigación en Ciencias Sociales, Asunción, v. 11, ed. 4, p. 223-240, 2 dez. 2015. Disponível em: http://scielo.iics.una.py/scielo.php?script=sci_arttext\&pid=S2226$40002015000200006 \& \operatorname{lng}=e s \& n r m=i s o \& t \operatorname{lng}=e s$. Acesso em: 9 dez. 2018.

MORAES, Thiago Perez Bernardes de. Cada cabeza su sentencia. Pena de muerte, cognición y sociedad. 1. ed. Saarbrücken: Editorial Académica Española,2016.

MORAES, Thiago Perez Bernardes de. TRILHA DE SANGUE: direitos humanos e a abolição da pena de morte. Confluências: Revista Interdisciplinar de Sociologia e Direito, Rio de Janeiro, v. 1, n. 21, p.164-181, jul. 2019. Disponível em: https://periodicos.uff.br/confluencias/article/view/34586/19990. Acesso em: 12 fev. 2020.

NELSON, Ediomo-Ubong E.; PATES, Richard. Supply control, demand reduction or harm reduction? Developments and directions for drug policy in Nigeria. Addiction Research \& Theory, London, v. 26, ed. 6, p. 1-5, 2018. Disponível em:

https://www.tandfonline.com/doi/full/10.1080/16066359.2017.1406480?scroll=top\&needAcc ess=true. Acesso em: 3 nov. 2019.

NIVEN, David; DONNELLY, Ellen A. Who challenges disparities in capital punishment?: An analysis of state legislative floor debates on death penalty reform. Journal of Ethnicity in Criminal Justice, Abingdon, v. 18, ed. 2, p. 95-122, 1 jan. 2020. Disponível em: https://www.tandfonline.com/doi/full/10.1080/15377938.2019.1710316. Acesso em: 7 set. 2020.

OBARISIAGBON, Emmanuel Imuetinyan. Congregation of the Condemned: Decades of Discontinuous Debates on Death by Design in Southern Nigeria. Mediterranean Journal of Social Sciences, London, v. 8, ed. 6, p. 91-98, 2 nov. 2017. Disponível em: https://www.mcser.org/journal/index.php/mjss/article/download/10111/9743. Acesso em: 9 abr. 2019.

SALEH-HANNA, Viviane. Colonial Systems of Control: Criminal justice in nigeria. 1. ed. Ottawa: University of Ottawa Press, 2008. 504 p. Disponível em: 
https://library.oapen.org/bitstream/handle/20.500.12657/31525/627412.pdf? sequence=1. Acesso em: 8 abr. 2019.

SHARIFIAN, Fariba; FEKRIPOUR, Katayoun; HEIDARPOUR, Azadeh. A Comparative Study of the Crimes Leading to the Death Penalty in the Quran, Zoroastrian Legal Sources, and the Penal Code of the Islamic Republic of Iran. Religious Inquiries, Qom, v. 9, ed. 17, p. 65-81, 3 fev. 2020. Disponível em:

http://ri.urd.ac.ir/article_113816_4d6d71d6f44f780ce908ca0fb90d4bb7.pdf. Acesso em: 4 mar. 2019.

TAWFIK, Ahmed Hamdy. The Concept of Crime in the Afghan Criminal Justice System: The Paradox between Secular, Tradition and Islamic Law: A Viewpoint of an International Practitioner. International Criminal Law Review, Leiden, v. 9, ed. 4, p. 667-687, 1 jan. 2009. Disponível em: https://brill.com/view/journals/icla/9/4/article-p667_5.xml Acesso em: 13 nov. 2018.

TELLENBACH, Silvia. Aspects of the Iranian Code of Islamic Punishment: The Principle of Legality and the Temporal, Spatial and Personal Applicability of the Law. International Criminal Law Review, Leiden, v. 9, ed. 4, p. 689-705, 1 jan. 2009. Disponível em: https://brill.com/view/journals/icla/9/4/article-p689_6.xml. Acesso em: 5 fev. 2020.

PEIFFER, Elizabeth. The Death Penalty in Traditional Islamic Law and as Interpreted in Saudi Arabia and Nigeria. William \& Mary Journal of Race, Gender, and Social Justice, Williamsburg, v. 11, ed. 3, p. 507-539, 5 abr. 2005. Disponível em: https://scholarship.law.wm.edu/cgi/viewcontent.cgi?article=1132\&context=wmjowl. Acesso em: 4 fev. 2020. 